\title{
Gut
}

Leading article

\section{Antimicrobial peptides in the gastrointestinal tract}

In contrast with the relative sterility of the small intestine, there is a large (approximately $10^{12}$ per gram content) and complex population of bacteria in the colonic lumen. ${ }^{1}$ Indeed, the gastrointestinal tract represents the largest area of interaction between the host and microorganisms. Overall the relation between the normal intestinal flora and the gastrointestinal tract is highly complex and not fully understood. Animal studies suggest that exposure to microorganisms is required for the normal development of the intestinal mucosa. ${ }^{1}$ However, the importance of the normal mucosal immune system in protecting the host as well as regulating the interactions with microorganisms is illustrated by the development of intestinal disease, predominantly in the presence of normal luminal flora, in animals in whom specific cytokine genes have been inactivated. $^{2}$

A variety of mechanisms are required to achieve relative sterility in the proximal gastrointestinal tract. Gastric acid represents an important barrier to ingested bacteria and peristaltic activity plays a major part in clearing microorganisms from the small intestine. Protective defence mechanisms are also operative at the mucosal level and can be divided into innate and adaptive immunity. The latter entails the development of specific responses embodied in the gastrointestinal immune system, in particular, the production of secretory IgA (sIgA) antibodies. A complex series of interactions between different cell types are required for the development of highly specific antibody mediated protection. A mucosal immune response is usually induced in Peyer's patches where B cells are stimulated. Committed B cells then migrate into the systemic circulation via mesenteric lymph nodes and thoracic duct. After emigration from the systemic circulation into the intestinal lamina propria, these cells mature into IgA producing plasma cells. Locally produced IgA is then transported across the epithelium by polymeric immunoglobulin receptor into the mucus layer where it inhibits attachment of microorganisms to epithelial cells ('immune exclusion'). However, the migration of antigen stimulated B cells from Peyer's patches to the intestinal lamina propria can take four to six days. ${ }^{3}$ As the proliferation rate of microorganisms is usually of greater magnitude, a much more rapidly responsive and/or preexisting, broad spectrum, antimicrobial defence is required. In the systemic circulation, such 'innate' immunity is mediated by a variety of molecules following phagocytosis by polymorphonuclear cells and monocytes. In the gastrointestinal tract such molecules may be active in the lumen or in the surface layer of mucus. The mucus layer, which overlies the surface epithelial cells, provides not only a physical barrier to bacteria and toxins but also contains $\operatorname{sigA}$ and lysozyme (which has antibacterial activity against Gram positive organisms). In addition, studies over the past few years suggest the presence of a novel form of innate immunity, which may be mediated in the lumen and at the mucosal surface, in the form of antimicrobial peptides. Members of three families of antimicrobial peptides, the defensins, magainins and cecropins have been isolated from the gastrointestinal tract of animals. In general, they are basic peptides, 20-40 amino acids in length (molecular weight 3-5 kDa) with potent activities against both Gram negative and Gram positive bacteria.

\section{Defensins}

Circulating polymorphonuclear cells and monocytes represent major systemic components of host defence against microbes, largely due to their capacity for phagocytosis. Polymorphonuclear cells are present in large numbers and after ingestion, can kill bacteria via oxygen dependent or oxygen independent mechanisms. The latter is mediated via antimicrobial polypeptides located in azurophil granules. They include bactericidal permeability increasing protein, cathepsin G, lysozyme, azurocidin as well as defensins. High concentrations of these molecules would be delivered during fusion of azurophil granules with phagosomes containing bacteria. Defensins were first purified from rabbit alveolar macrophages and polymorphonuclear cells and subsequently from human polymorphonuclear cells (and designated HNP 1-4) in the mid 1980 s. $^{4}$ The defensins constitute $30-50 \%$ of azurophil granule protein and greater than $5 \%$ of the total protein content in human and rabbit polymorphonuclear cells. ${ }^{5}$ They are small, cationic, arginine rich peptides containing 29-35 amino acids. Within the family, there is absolute conservation of six cysteine residues, which leads to the formation of three disulphide bonds that are essential for antimicrobial activity. In vitro studies using defensins purified from human polymorphonuclear cells have shown their capacity to kill a wide range of Gram positive and Gram negative bacteria and fungi as well as protozoa such as Gardia lamblia. This systemic form of innate immunity is elicited in the intestinal mucosa and the lumen after direct invasion by pathogenic microorganisms or mucosal injury induced by secreted toxins. Polymorphonuclear cells 
are attracted into the mucosa after secretion of a wide range of chemotactic molecules, and into the lumen in response to chemotactic factors derived from bacteria. Epithelial cells are the first host cells that would be affected by pathogenic bacteria or their products. Recent studies have shown that these cells are capable of producing interleukin 8, a potent chemoattractant for polymorphonuclear cells, after direct invasion by bacteria ${ }^{6}{ }^{7}$ or injury induced by their toxic products. ${ }^{8}$

Recent studies have shown that members of the defensin family are also produced by intestinal Paneth cells in mammals. ${ }^{9-12}$ These mucosal defensins may provide the first line of innate protection against microbes, before polymorphonuclear cell derived systemic innate immunity is elicited. Expression of defensin transcripts in mouse Paneth cells was first reported by Ouellette and colleagues who designated these molecules cryptdins. ${ }^{9}$ To date, six cryptdin peptides have been isolated from mouse small intestine and amino acid sequence analysis has demonstrated the presence of six distinctive cysteine residues, in common with the other members of the defensin family. An additional 11 cryptdin mRNA isoforms have been characterised from a cDNA library generated by PCR amplification of a single jejunal crypt. ${ }^{13}$ Most of the isolated and sequenced as well as the predicted mature isoforms of cryptdin show a high degree of conservation. However, it is possible that the presence of numerous isoforms of cryptdin may mediate different levels of activity against a broad range of bacterial species in the intestine. Thus, in in vitro assays against Escherichia coli, cryptdin 4 was shown to be the most active out of the six peptides. ${ }^{13}$

Complementary DNA clones of rabbit and human myeloid defensins as well as mouse cryptdins have shown that they are synthesised as $93-96$ amino acid polypeptides consisting of a 19 residue signal sequence and 40-45 amino acid propeptide. ${ }^{4}$ There is a high degree of similarity in the signal sequence of members of the defensin family and this was exploited to identify genes for new members of the family in humans. ${ }^{14}{ }^{15}$ They have been designated defensin- 5 and -6 (HNP 1-4 being considered by these investigators to be defensins 1-4, however the original terminology for the polymorphonuclear cell defensins continues to be used by other investigators) and their transcripts are highly expressed in Paneth cells of the small intestine. ${ }^{14}{ }^{15}$ Recently, potent antimicrobial activity by peptidic extracts from human terminal ileal mucosa has also been shown. ${ }^{16}$

To date, only the mouse small intestinal mucosal defensins have been isolated and characterised. However, the site at which they mediate their antimicrobial activities in vivo remains to be determined. While they have been shown to be present in Paneth cells, the mucus layer, and the lumen, the range and potency of individual peptides in the milieu of the mucous layer and the lumen is unknown. It is also possible that, as for polymorphonuclear cells, the mucosal defensins mediate their activity intracellularly within the Paneth cells.

Paneth cells are found at the base of crypts and are characterised by the presence of large eosinophilic granules. The functions of these cells are not fully understood. They have been shown to express a variety of peptides and proteins in addition to defensins. These include lysozyme, ${ }^{17}$ tumour necrosis factor $\alpha,{ }^{18}$ and guanylin (an endogenous ligand of receptors for $E$ coli heat stable enterotoxin (STa)). ${ }^{19}$ In addition to being secretory cells, Paneth cells have also been reported to be capable of phagocytosis. ${ }^{20}$ It is therefore possible that antimicrobial activity of defensins is mediated predominantly within phagosomes in Paneth cells where high concentrations of the peptides can be delivered. Although absent from normal colon, Paneth cell metaplasia occurs in inflammatory bowel disease ${ }^{21}$ and this response is likely to result from increased penetration by luminal microorganisms.

\section{Magainins}

Magainins are linear peptides (less than 30 amino acids) devoid of cysteine residues and are active against a wide range of Gram positive and Gram negative bacteria, fungi, and protozoa. ${ }^{22}$ They were first isolated from the skin of the African clawed frog, Xenopus laevis, by Zasloff and colleagues. ${ }^{23}$ Their identification followed investigation into the capacity of frog skin wounds to heal without any sign of infection. This was despite the presence of pathogenic organisms in the water tanks in which the animals were kept. ${ }^{22}$ A number of magainin antimicrobial peptides have subsequently been isolated from the stomach of Xenopus laevis. ${ }^{24}$ They are stored in multi-nucleated granular cells with capacity for secretion into the gastric lumen. Genes for two members of the magainin family (magainin and PGLa) have recently been shown to be expressed in the small intestine of Xenopus laevis. ${ }^{25}$ They are localised to large granule filled cells, which have features in common with the defensin expressing mammalian Paneth cells. Magainin-like immunoreactivity has also been demonstrated in epithelial cells of human submandibular and labial salivary glands. ${ }^{26}$ Peptides belonging to this family would therefore be expected to be present in the saliva to mediate antimicrobial activity in the oral cavity.

\section{Cecropins}

Cecropins were originally isolated from haemolymph of the cecropia moth after infection with bacteria. ${ }^{27} \mathrm{~A}$ member of this family, designated cecropin P1 has been isolated from porcine proximal small intestine $\mathrm{e}^{28}$ and has been localised to epithelial cells of the duodenum as well as glucagon positive cells of the pancreas. ${ }^{29}$ It is a 31-residue linear peptide devoid of cysteine. Interestingly, its antimicrobial activity seems to be restricted to Gram negative bacteria (with moderate or no activity against Gram positive bacteria). ${ }^{28}$

\section{Proline rich and arginine rich antimicrobial peptides}

After isolation of cecropin P1, further studies of extracts of porcine proximal small intestine led to the isolation of another antimicrobial peptide, designated PR-39 (proline rich, arginine rich with 39 residues). ${ }^{30}$ Subsequent cDNA cloning has shown that the gene for PR-39 is expressed in the bone marrow. ${ }^{31}$ The cells expressing PR-39 in the pig intestine have not been characterised but it is possible that it is produced by bone marrow derived cells present in the lamina propria.

\section{Conclusion}

Studies over the past few years have shown a novel form of innate immunity in the gastrointestinal tract of animals in the form of antimicrobial peptides. It is probable that other members of known families and possibly also new families of antimicrobial peptides will be identified in the gastrointestinal tract of animals. Future studies should also elucidate the in vivo importance of these molecules not only in restricting the normal bacterial flora to the colonic lumen but also in protecting the host against invasion. With the increasing use of proton pump inhibitors, which 
may compromise gastric acid mediated antimicrobial protection, the ability to up regulate expression of mucosal antimicrobial peptides could be therapeutically beneficial. Indeed, recent studies suggest that such up regulation may occur in diseased mucosa in vivo; epithelial cell expression of an antimicrobial peptide has been shown to be induced in association with acute and chronic inflammation in the lamina propria. ${ }^{32}$

Y R MAHIDA

F ROSE

Division of Gastroenterology,

W C CHAN

University Hospital,

Queen's Medical Centre,

Nottingham

and

Department of Pharmaceutical Sciences,

University of Nottingham

Correspondence to: Dr Y R Mahida, Division of Gastroenterology, University Hospital, Queen's Medical Centre, Nottingham NG7 2UH.

1 Simon GL, Sherwood LG. Normal alimentary tract microflora. In: Blaser MJ, Smith PD, Ravdin JI, Greenberg HB and Guerrant RL, eds. Infections of the gastrointestinal tract. New York: Raven Press, 1995; 53-69.

2 Elson CO, Sartor RB, Tennyson GS, Riddell RH. Experimental models of inflammatory bowel disease. Gastroenterology 1995; 109: 1344-67.

3 Hall J. Lymphocyte recirculation and the gut: the cellular basis of humoral immunity in the intestine. Blood Cells 1979; 5: 479-92.

4 Lehrer RI, Lichtenstein AK, Ganz T. Defensins: antimicrobial and cytotoxic peptides of mammalian cells. Annu Rev Immunol 1993; 11: 105-28.

5 Lehrer RI, Ganz T, Selsted ME. Defensins: endogenous antibiotic peptides of animal cells. Cell 1991; 64: 229-30.

6 Eckmann L, Kagnoff MF, Fierer J. Epithelial cells secrete the chemokine interleukin-8 in response to bacterial entry. Infect Immun 1993; 61: 4569-74.

7 McCormick BA, Colgan SP, Delp-Archer C, Miller SI, Madara JL. Salmonella typhimurium attachment to human intestinal epithelial monolayers: transcellular signalling to subepithelial neutrophils. $\mathcal{f} \mathrm{Cell}$ Biol 1993; 123: 895-907.

8 Mahida YR, Makh S, Hyde S, Gray T, Borriello SP. Effect of Clostridium difficile toxin $\mathrm{A}$ on human intestinal epithelial cells: induction of interleukin-8 production and apoptosis following cell detachment. Gut 1996; 38: 337-47.

9 Ouellette AJ, Greco RM, James M, Frederick D, Naftilan J, Fallon JT. Developmental regulation of cryptdin, a corticostatin-defensin precursor mRNA in

10 Ouellette AJ, Miller SI, Henschen AH, Selsted ME. Purification and primary structure of murine cryptdin-1, a paneth cell defensin. FEBS 1992; 304: 146-8.

11 Selsted ME, Miller SI, Henschen AH, Ouellette AJ. Enteric defensins: antibiotic peptide components of intestinal host defense. F Cell Biol 1992; 118: $929-36$
12 Eisenhauer PB, Harwig SSSL and Lehrer RI. Cryptdins: antimicrobial defensins of the murine small intestine. Infect Immun 1992; 60: 3556-65.

13 Ouellette AJ, Hsieh MM, Nosek MT, Cano-Gauci DF, Huttner KM, Buick $\mathrm{RN}$, et al. Mouse paneth cell defensins: primary structures and antibacterial activities of numerous cryptdin isoforms. Infect Immun 1994, 62: 5040-7.

14 Jones DE, Bevins CL. Paneth cells of the human small intestine express an antimicrobial peptide gene. $\mathcal{F}$ Biol Chem 1992; 267: 23216-25.

15 Jones DE, Bevins CL Defensin-6 mRNA in human paneth cells: implications for antimicrobial peptides in host defense of the human implications for antimicrobial pept

16 Rose F, Chan WC, Mahida YR. Human terminal ileal mucosa expresses novel antimicrobial activity. Gut 1995; 36 (suppl 1): A64.

17 Erlandsen SL, Parsons JA and Taylor TD. Ultrastructural immunocytochemical localization of lysozyme in the paneth cells of man. $\mathcal{F}$ Histochem Cytochem 1974; 22: 401-13.

18 Keshav S, Lawson L, Chung LP, Stein M, Perry VH, Gordon S. Tumour necrosis factor mRNA localised to paneth cells of normal murine intestinal epithelium by in situ hybridisation. F Exp Med 1990; 171: 327-32.

19 de Sauvage FJ, Keshav S, Kuang WJ, Gillett N, Henzel W, Goeddel DV. Precursor structure, expression and tissue distribution of human guanylin. Proc Natl Acad Sci USA 1992; 89: 9089-93.

20 Erlandsen SL, Chase DG. Paneth Cell Function: phagocytosis and intracellular digestion of intestinal microorganisms. F Ultrastruct Res 1972 ; 41: 296-318.

21 Paterson JC, Watson SH. Paneth cell metaplasia in ulcerative colitis. $\mathrm{Am}$ F Pathol 1961; 38: 243-9.

22 Berkowitz BA, Bevins CL, Zasloff MA. Magainins: A new family of membrane-active host defense peptides. Biochem Pharmacol 1990; 39: 625-9.

23 Zasloff M. Magainins, a class of antimicrobial peptides from Xenopus skin: isolation, characterization of two active forms, and partial cDNA sequence of a precursor. Proc Natl Acad Sci USA 1987; 84: 5449-54.

24 Moore KS, Bevins CL, Brasseur MM, Tomassini N, Turner K, Eck $\mathrm{H}$ et al. Antimicrobial peptides in the stomach of Xenopus laevis. $\mathcal{F}$ Biol Chem 1991; 266: 19851-7.

25 Reilly DS, Tomassini N, Bevins CL, Zasloff M. A paneth cell analogue in Xenopus small intestine expresses antimicrobial peptide genes: conserva-
tion of an intestinal host-defense system. 7 Histochem Cytochem 1994; 42: tion of an in

26 Wolff A, Moreira JE, Bevins CL, Hand AR, Fox PC. Magainin-like immunoreactivity in human submandibular and labial salivary glands. $\mathscr{f}$ Histochem Cytochem 1990; 38: 1531-4.

27 Boman HG. Antibacterial peptides: key components needed in immunity. Cell 1991; 65: 205-7.

28 Lee J-Y, Boman A, Chuanxin S, Andersson M, Jornvall H, Mutt V, et al. Antibacterial peptides from pig intestine: isolation of a mammalian cecropin. Proc Natl Acad Sci USA 1989; 86: 9159-62.

29 Lundberg NM, Hemsen A, Andersson M, Hokfelt T, Mutt V, Boman HG Cecropin P1-like immunoreactivity in epithelial cells of duodenum and glucagon cells of the pancreas. Acta Physiol Scand 1991; 141: 443-4.

30 Agerberth B, Lee J-Y, Bergman T, Carlquist M, Boman HG, Mutt V, et al. Amino acid sequence of PR-39, isolation from pig intestine of a new member of the family of proline-arginine rich antibacterial peptides. FEBS 1991; 202: 849-54.

31 Storici P, Zanetti M. A cDNA derived from pig bone marrow cells predicts a sequence identical to the intestinal antibacterial peptide PR-39. Biochem Biophys Res Commun 1993; 196: 1058-65.

32 Schonwetter BS, Stolzenberg ED, Zasloff MA. Epithelial antibiotics induced at sites of inflammation. Science $1995 ; 267: 1645-8$. 